\title{
Exploration and practice of University Computer Specialty Curriculum Examination Reform
}

\author{
Yali Feng ${ }^{a}$, Ping Zhang ${ }^{b}$ \\ School of Northeast Petroleum University, Daqing 163000, China \\ ayalifeng@163.com, bpingzhang@126.com
}

Keywords: Curriculum; Test method; Examination reform; Innovative Practices.

\begin{abstract}
Examination is an important method of knowledge degree evaluation process for students to master. Through the examination reform causes students in attach great importance to the basic knowledge of learning. At the same time, pay more attention to the formation of the cultivation of practice ability and innovation spirit. At present, there are still many problems in the course examination method in universities. With summarizing the existing curriculum on the basis of the examination reform way, put forward the increase in written examination of individual subjects, as well as in the computer professional course examination <Algorithms and Data Structures $>$ to trial implementation. Practice proved that the examination reform scheme is feasible and satisfactory results have been achieved, so it has a certain promotion value.
\end{abstract}

\section{Introduction}

Examination is a kind of important methods of the evaluation in teaching effect. If still adopt the traditional mode of talent development has been unable to meet the needs of new situation. Through the mode of examination reform should adapt to the talent evaluation. Assessment and evaluation of detection on student achievement is very important. On the one hand, it can test the students' study effect. On the other hand, can also reflect the extent of which students grasp the teaching content. Make students to learn knowledge deepen understanding through the appraisal of teaching content. Especially like the course of computer which is mainly operate the process consisting of professional. Through the test in the actual operation platform appears to investigate whether students really master the relevant knowledge and skills or not. As well as if they can use the technology which learned in order to practice in the further work.

\section{The Current Existing Problem In Examination Method}

Due to our country for a long time put exam-oriented education teaching effect test first which result in the college course exam exist some issues still need to be resolved, such as the following:

(1) The weight distribution of the professional course exam is not reasonable. Test proportion of objectivity, comprehensive thinking questions and analysis discussed are less; while rote class problem, analysis of problem and less innovation. The formation of the irrational distribution of questions will be the cultivation of comprehensive ability of students and the spirit of innovation effect.

(2) The way detection the score of exam cause misleading student achievement. Some kinds of subjective topic which only pay attention to the accuracy of the results. While ignoring the students' analysis so that give the students chances of cheating in the exam.

(3) To detect students' achievement test method is too single. There are some conducive won't good for the students active learning in a single factor test.

(4) The test cognitive purposes are error. Students are not fully aware of the "exam oriented" function which makes some students study before the exam just for the examination and the final score. It means they only want high scores not really for the knowledge to get. Therefore, the reform of college curriculum examination methods is necessity. 


\section{The Malpractice Of Examination On The Content And Assessment Methods}

(1) At the moment mostly exam content is still focused on basic knowledge, to ignore the inspection ability, quality and innovation level. In the mode of grading, pay attention to the standardization of the answer and standardization. This kind of exam and score, the biggest drawbacks is the impact on the quality of personnel training, especially for the cultivation of innovative talents in [1].

(2) Single exam forms and methods to cultivate practical ability is constrained [2].

(3) Many educators according to the characteristics of different subjects and courses proposed many effective solutions, constructs the comprehensive evaluation more scientific and reasonable system. Just talk about the methods of entrance examination, there is closed book, open book, semi open book, written examination, interview, discussion, operation, report, literature review, curriculum design and case etc. However, at present in our country university course exam is still one-time final request. Dominant and generally not out of the orbit of exam-oriented education so that become the bottleneck of restricting the cultivating high-quality innovative talents [3].

(4) There is only a normal course final exam opportunity in the university, and the final one examination is limited by the papers, examination time and capacity constraints so that cannot comprehensively and objectively accurately reflect the whole process of teaching.

(5) There are many problems in the test type, such as test method is too simple, pay more attention to knowledge while light to ability. Attach importance to the result while light process. These problems lead to the direct result is that cultivate the students' ability and professional talent training scheme of the objectives.

\section{The Reform Of Current Examination Implementation Method}

Currently both our country and abroad focus on the use of the reform curriculum examination mode have the following:

(1) Use an open-book way in the course exam method to replace the original request for the answer pattern. An open-book exam test content in theory with the practice of open questions. This way of examination mainly investigates the students with the knowledge to analysis problem which solving ability and innovation spirit. But the open-book exam just is a kind of form and the content is still accounts for the dominant position in comparative economics, so it lost the open-book exam should be.

(2) Written + oral test combined manner. Use the oral test, pumping test to answer the questions on scene. Use the written test closed book form general. But in the current, in the condition of mostly used, the teacher's workload increase greatly in order that increase the difficulty of implementing [4].

\section{Exploration And Practice Of Reform In The Examination Method Of Computer Curriculum}

My tutor and I have carried on the method of computer "algorithm and data structure" course in the examination and get the beneficial exploration and reform. For the subjective topic in joined a large number of using personalized topic which mufti problem solving in the form so that students in the examination can make full use of their learned knowledge theory make the answer. A true reflection of the students is the level of learning. On the basis my tutor declared the Hei Longjiang educational science planning projects in 2013 and approved the project. The title is "the research of evaluation methods based on the teaching effect of examination in Colleges and universities". Following the 2011 session of the "data structure and algorithm" examination continue to carry out the way of reform and got good results.

Join the "individuality question" in the new specialized course examination. The individual item is mainly by the same title for every students but they will get different answers finally. We emphasize the reform of examination, but cannot simply deny the role of other objective questions in the traditional way. Therefore we let the objective questions, subjective and individual item combination 
in order to make them play a good role in their respective. In addition to join in the small paper in computer professional course exam and defense, computer-based assessment of a variety ways. Specific use scheme is as follows:

(1) To the students test mode using a roll of one question derived $\mathrm{N}$ volume method, that is increase the subjective part in the proportion of individual questions written. Due to the personality examination paper is effective discover the achievement of students? The same questions in the paper show the students' subjective learning ability form different given answers which fully reflect its mufti solution to one problem the characteristics of flexibility and diversity.

(2) The machine test parts require students to make electronic operation and report on the experimental machine. In the experiments reported apart from the provisions of the content also includes the experience of learning experiences. Teachers through two aspects content to make the authenticity of testing a student's work level. In each module of learning a great assignment and set the job evaluation results a bigger weight.

Adopting the form of examination mode has the following characteristics:

(1)Based on the old exam mode gradually increase the new personality until the students adapt to the new test model. To make the greatest degree of optimization and improve the quality for the students' objective investigation of teaching, learning situation.

(2) In the new examination mode not abandon the traditional theory of knowledge. The future focus on the examination content, the whole process, multiple forms of assessment methods to investigate students' knowledge, ability, quality and the formation of the objective that is just evaluation on students. To guide the students study independently and help teachers to improve the teaching effect. In order to enhance the students' ability of autonomous learning.

(3) Carry out the flexible ways of examination. For some students in the computer experiments have the phenomenon of plagiarism mainly on the implementation of the method is: when answer the question make students to hand in electronic assignments and use the computer experimental report. Besides the content of the provisions in the experiment report including the learning experience. Through the evaluation results of homework set larger weight so that the students can faced with positive thinking and consult with each other to improve the learning enthusiasm. Thus to improve the students' ability of independent operation and practical application.

In this paper, statistical and calculate the different category variance values of the student's grade. The variance formula as shown below:

$$
\sigma^{2}=\frac{\sum_{i=1}^{n}\left(x_{i}-M\right)^{2}}{n}
$$

Randomly selected five adopted personalized item class scores and grades of different category title variance value statistics, statistical results as shown in Table 1.

Table 1 Three Scheme comparing

\begin{tabular}{ccccc}
\hline \multirow{2}{*}{ Class } & \multicolumn{2}{c}{ Subjective } & \multicolumn{2}{c}{ Objective } \\
\cline { 2 - 5 } & Choice & $\begin{array}{c}\text { Blank } \\
\text { Filling }\end{array}$ & $\begin{array}{c}\text { The usual } \\
\text { questuins }\end{array}$ & $\begin{array}{c}\text { Presonalized } \\
\text { question }\end{array}$ \\
\hline Information class11-1 & 1.49 & 3.43 & 14.5 & 26.2 \\
Information class11-2 & 2.38 & 4.41 & 16.8 & 23.6 \\
Applied Mathematics class 11-1 & 1.76 & 3.48 & 19.7 & 28.2 \\
Applied Mathematics class 11-2 & 2.51 & 4.52 & 17.2 & 36.7 \\
Information calculation class11-1 & 1.96 & 3.52 & 20.3 & 35.4 \\
The average value of variance & 2.41 & 4.12 & 17.6 & 25.7 \\
\hline
\end{tabular}

Further on the grade distribution personality professional computer course class of "algorithms and data structures" examination questions to carry on the analysis. The results of the analysis show that student's achievement obeys normal distribution which can accurate measurement students grasp the knowledge reasonably. The variance is an important index of evaluation the student's achievement. The significance is how the responded to set a data dispersion or fluctuation degree. 
The large variance show achievements fluctuation is big while the variance of the score low means it is small. The table variance in 1-1 value can be seen, the objective questions just like choose and blank filling in the values were 2.41 and 4.12 . However the variance of personalized questions and the usual questions were 25.7 and 17.6. The results show, the objective questions square reflects the fluctuation is small and produce this result has the following two kinds of circumstances:

(1) The students master the theoretical knowledge is solid so their answer level is similar.

(2) Objective topic mainly includes selection and blanks filling so that exist the possibility of plagiarism.

Subjective question variance fluctuation higher means the students' scores quite bigger. So less possibility of plagiarism in the exam. Subjective questions is better to show whether students have mastered the knowledge in real or not than the objectives. Meanwhile in the subjective questions we can see the personalized subject variance 8.1 higher than the conventional questions. Introduction of personalized text of the proposed topic suggests. More objectively reflect teaching and objective questions on standardized tests to avoid exposed some drawbacks.

The above results show that appropriately increase the examination way of joining the program in computer practice topic. This will not only reduce the teachers' heavy marking task quantity but also make the students use more brains, diligence hands and mobilize the enthusiasm of students in active learning. Finally, assessment course papers and the defense are also very important. The thesis plays a role of catalyst in the examination process which can strengthen the enthusiasm of students' autonomous learning. Cultivate students to read more books and have a good habit of check literature. The most important is communicate with their teachers and make more discussion in reply process which mobilize the enthusiasm of the two aspects teaching and learning. Examination is an important part of teaching process while if only to judge the learning effect of students "scores is the only performance" negative performance and the phenomenon of cheating in college examination is repeated. So join the Individual item can curb this phenomenon in some extent.

College Students' learning style is not equal to the primary and secondary school students everything based on the teachers orders. However, existing teaching ways in Colleges and universities is that teachers speaking then students followed. Students too much dependence on textbooks and teachers thus restricting students' thinking ability, devoid the students learning potential. Select the teaching content, the choice of teaching method, students' ability and failed to ascend or integrate. According to the college students' education should stimulate their independent learning ability. At present some enterprises have a prejudice on college students.

\section{References}

[1] Ji Xueshi et al. 2006. Theory of examination reform. Science education (4): 11-12.

[2] Jiang Ping et al. 2008. Exploration and practice of the reform of curriculum examination method. Teaching research of refrigeration and air conditioning of subject education (6): 281-284.

[3] Liu Jianguo. 2006. Innovative talents cultivation and examination reform in colleges and universities. The modern university education (2): 107-110.

[4] Shen Binliang et al. 2006. Cultivating innovative talents. Jiang Su Higher Education (3): 91-93. 